\title{
The Synthesis of the Glycopolymers Containing Pendant D,L-Xylaric and L-Tartaric Moieties and Their Inhibition Behavior on the $\beta$-Glucuronidase Activity
}

\author{
By Asei William KAWAGUCHI, Takafumi KAIDA, Haruki OKAWA, and Kazuhiko HaShIMoto*
}

\begin{abstract}
New styrene derivatives having D,L-xylaric and L-tartaric moieties, $N$ - $p$-vinylbenzyl-D,L-xylaramic and $N$ - $p$-vinylbenzyl-Ltartaramic acids (VB-D,L-XylarH $\underline{10}$ and VB-L-TartaH 11), were synthesized by the ring-opening reaction of 2,3,4-tri- $O$ acetyl-meso-xylaric anhydride and 2,3-di- $O$-acetyl-L-tartaric anhydride with $p$-vinylbenzylamine, respectively, and their subsequent hydrolysis under basic condition. The glycomonomers were copolymerized with acrylamide (AAm) to give novel polymers having xylaric and tartaric moieties in the pendants (P(VB-D,L-XylarH-co-AAm) 12 and P(VB-L-TartaH-co-AAm) 13) respectively. The inhibition abilities of the resulting glycopolymers on the $\beta$-glucuronidase activity were found to be much higher than not only that of the corresponding saccharic acids but also that of the glycomonomers, especially at the lower concentration of saccharic unit by the spectrophotometry. However, the inhibition values were lower than those of the

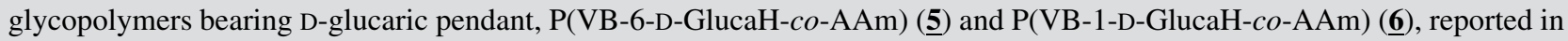
our previous work. The Lineweaver-Burk plot suggested that the glycopolymer 13 and the corresponding monomer 11 inhibit the $\beta$-glucuronidase activity noncompetitively, whereas the inhibition behavior of glycopolymer $\underline{\mathbf{1 2}}$ and monomer $\underline{\mathbf{1 0}}$ is more complicated, probably a mix-type of uncompetitive and noncompetitive ones. These are in contrast to the competitive inhibition in the presence of the glycopolymer $\underline{\mathbf{5}}$ and its monomer $\underline{\mathbf{1}}$.

KEY WORDS: Glycopolymer / Xylaric Acid / Tartaric Acid / $\beta$-Glucuronidase / Inhibitor / Xenobiotics /
\end{abstract}

When xenobiotics such as toxic and medical substances are absorbed into the human body, they are sent to the liver and oxidized to $\beta$-glucuronide conjugates. ${ }^{1}$ This reaction is a kind of detoxication metabolism. If the molecular weight of the conjugates is more than 400 , they should be exhausted via the small intestines. However, most of them are hydrolyzed by the $\beta$-glucuronidase in the small intestine. The free xenobiotics are absorbed and returned to the liver to be metabolized again. ${ }^{1}$ If the xenobiotics are toxic, this cycle may be serious for health. Therefore the inhibition of the $\beta$-glucuronidase activity would be effective for exhausting of the xenobiotics from the body. ${ }^{2-7}$

D-Glucaric acid and their lactone derivatives are known to be efficient inhibitors for $\beta$-glucuronidase. ${ }^{8-16}$ However, even if these saccharic derivatives were administered orally, they would be absorbed before reaching the small intestine.

In our previous work, ${ }^{5-7}$ four styryl-type monomers having D-glucaric, L-gulonic, and D-gluconic moieties, $N$ - $p$-vinylbenzyl-6-D-glucaramic acid (VB-6-D-GlucaH, 1), $N$-p-vinylbenzyl-1-D-glucaramic acid (VB-1-D-GlucaH, 2), $N$ - $p$-vinylbenzyl-6-L-gulonamide (VB-6-D-Glco, $\underline{\mathbf{3}}$ ), and $N$-p-vinylbenzyl-6D-gluconamide (VB-6-D-Glco, $\underline{\mathbf{4}}$ ), were synthesized through the ring-opening reaction of D-glucaro-6,3-lactone, D-glucaro1,4-lactone, L-gulono-1,4-lactone and D-glucono-1,5-lactone, respectively, with $p$-vinylbenzylamine. Although these lactones are commercially available, D-glucarolactones are relatively expensive and prepared from D-glucose.

The water soluble random copolymers of $\underline{\mathbf{1}}$ and $\underline{\mathbf{2}}$ with acrylamide, poly $(N$ - $p$-vinylbenzyl-6-D-glucaramic acid-co-<smiles>Cc1ccc(CNC(=O)C(O)C(O)C(O)C(O)C(=O)O)cc1</smiles>

VB-6-D-GlucaH, 1

Scheme 1.<smiles>CCc1ccc(CNC(=O)C(O)C(O)C(O)C(O)C(=O)O)cc1</smiles>

VB-1-D-GlucaH, $\underline{2}$

Scheme 2.

acrylamide) (P(VB-6-D-GlucaH-co-AAm), $\underline{\mathbf{5}})$, poly( $N$ - $p$-vinylbenzyl-1-D-glucaramic acid-co-acrylamide) (P(VB-1-DGlucaH-co-AAm), $\underline{\mathbf{6}}$ ), respectively, were found to suppress 
<smiles>CCc1ccc(CNC(=O)C(O)C(O)C(O)C(O)CO)cc1</smiles>

VB-6-D-GICo, $\underline{3}$

Scheme 3.<smiles>CCC1CCC(CC(N)=O)CC1C(=O)NCc1ccc(C(O)C(O)C(O)C(O)C(=O)O)cc1</smiles>

P(VB-6-D-GlucaH-co-AAm), $\underline{5}$

Scheme 5

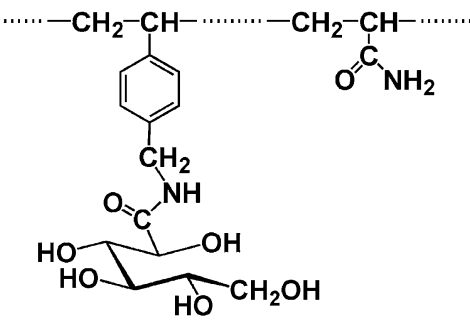

P(VB-6-D-GIco-co-AAm), $\underline{7}$

Scheme 7.

the hydrolysis of a model compound for the xenobiotics- $\beta$-Dglucuronide conjugates, $p$-nitrophenyl $\beta$-D-glucuronide (9). However, the copolymers, poly( $N$-p-vinylbenzyl-6-L-gulonamide-co-acrylamide) (P(VB-6-D-Glco-co-AAm), 7), and poly( $N$ - $p$-vinylbenzyl-1-D-gluconamide-co-acrylamide) (P(VB-1D-Glco-co-AAm), 8), respectively, scarcely inhibited the hydrolysis (Scheme 9). ${ }^{5-7}$ Therefore the absence of the carboxy group in the glycopolymers $\underline{\mathbf{7}}$ and $\underline{\mathbf{8}}$ should be a main reason for their poor inhibition ability. Moreover, the kinetic analysis of the hydrolysis using Lineweaver-Burk plot ${ }^{17,18}$ suggested that glycopolymer $\underline{\mathbf{5}}$ inhibits the enzyme competitively but the glycopolymer $\underline{\mathbf{6}}$ does uncompetitively. ${ }^{5,7}$

The inhibition behavior is roughly classified into three kinds that are competitive, noncompetitive and uncompetitive. Competitive inhibition is that the inhibitor binds to the active site of the enzyme to form the enzyme-inhibitor complex (EI) and prevent the substrate binding the same site of the enzyme. Noncompetitive inhibition takes place when the inhibitor binds

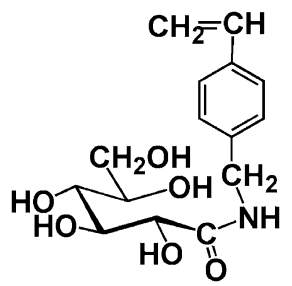

VB-1-D-GIco, 4

Scheme 4.<smiles>CCCc1ccc(CNC(=O)C(O)C(O)C(O)C(O)C(O)C(=O)O)cc1</smiles>

P(VB-1-D-GlucaH-co-AAm), $\underline{6}$

Scheme 6.

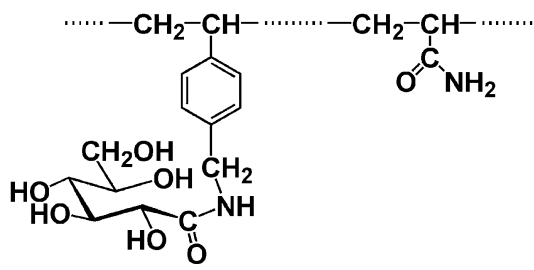

P(VB-1-D-Glco-co-AAm), $\underline{8}$

Scheme 8.

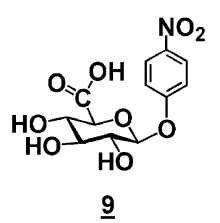

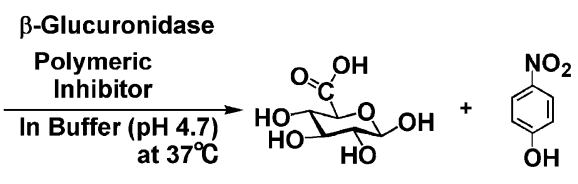

UV 400nm
Scheme 9.

to both the enzyme and the enzyme-substrate complex (ES) and becoming EI and the enzyme-substrate-inhibitor complex (ESI). Uncompetitive inhibition occurs when the inhibitor binds to only the enzyme-substrate complex (ES) to form ESI. EI and ESI are inactive, respectively.

In order to examine the inhibition of the glycopolymers containing five- and four-carbon saccharic pendants, two new glycomonomers, $N$ - $p$-vinylbenzyl-D,L-xylaramic acid (VB-D,L$\mathrm{XylarH}, \underline{\mathbf{1 0}}$ ) and $N$-p-vinylbenzyl-L-tartaramic acid (VB-LTartaH, 11), respectively, were synthesized in this article. The 


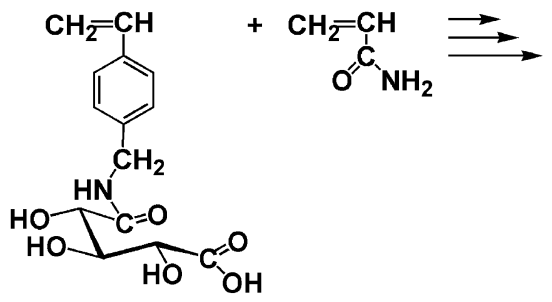

VB-D,L-XylarH, $\underline{10}$

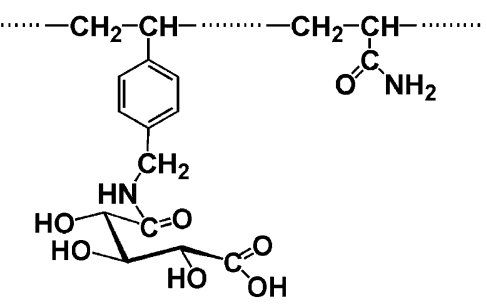

P(VB-D,L-XylarH-co-AAm), 12

Scheme 10.<smiles>C=Cc1ccc(CNC(=O)C(O)C(O)C(=O)O)cc1</smiles>

VB-L-TartaH, $\underline{11}$<smiles>C#CC(=O)CC=CC(N)C#C</smiles>

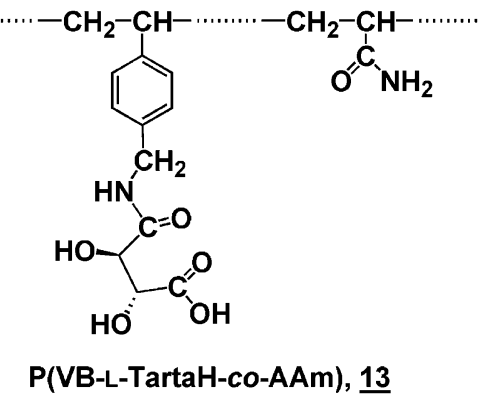

Scheme 11.

inhibition behavior of their random copolymers with acrylamide, $\operatorname{Poly}(N$ - $p$-vinylbenzyl-D,L-xylaramic acid-co-acrylamide) and Poly( $N$ - $p$-vinylbenzyl-L-tartaramic acid-co-acrylamide) (P(VB-D,L-XylarH-co-AAm), $\underline{\mathbf{1 2}}$ and P(VB-L-TartaHco-AAm), 13), was also investigated kinetically and compared with that of the corresponding glycomonomers and saccharic acids.

\section{EXPERIMENTAL}

\section{Materials}

2,3,4-Tri- $O$-acetyl-meso-xylaric anhydride was synthesized from acetic anhydride and xylaric acid which was previously prepared through the oxidation of D-xylose with nitric acid. ${ }^{19}$ $p$-Vinylbenzylamine was obtained through the azidation of $p$ vinylbenzyl chloride and the following reduction with lithium aluminum hydride. ${ }^{20} p$-Vinylbenzyl chloride was kindly supplied by Seimi Chemical Co. Ltd. (Chigasaki, Kanagawa, Japan). meso-Xylose and 2,3-diacetyl-L-tartaric anhydride were purchased from Tokyo Kasei Co. Ltd. 28\%-Ammonia aqueous solution was obtained from Taisei Kagaku Co. Ltd. $\beta$ Glucuronidase (bovine liver) and $p$-nitrophenyl $\beta$-glucuronide were purchased from Sigma and used as received. DMSO was dried over calcium hydride and distilled under reduced pressure.

\section{Instruments}

${ }^{1} \mathrm{H}$ NMR spectra were taken with a JEOL JNM-EX-270 Fourier transform high-resolution spectrometer. Size-exclusion liquid chromatography was measured with a TOSOH model HLC-8120 high-performance liquid chromatogram apparatus using TOSOH TSK-gel $\alpha$-M, $\phi 7.8 \times 600 \mathrm{~mm}$ in acetic buffer solution $\left(0.8 \mathrm{~mL} / \mathrm{min}\right.$.). Molecular devise SPECTRSA $_{M A X}{ }^{\mathrm{TM}}$ 250 microplate spectrophotometer was used for determination of $p$-nitrophenol generating during the hydrolysis test. Optical rotation was determined with a P1010 (JASCO) polarimeter.

\section{Monomer Synthesis}

VB-D,L-XylarH (10) $)$ was prepared as follows: $4.8 \mathrm{~g}$ (17 mmol) of 2,3,4-tri- $O$-acetylxylaric anhydride and $4.5 \mathrm{~g}$ (3.4 mmol) of $p$-vinylbenzylamine were stirred in $53 \mathrm{~mL}$ of ethyl acetate at $40^{\circ} \mathrm{C}$ for $1 \mathrm{~d}$, and the solvent was distilled out under reduced pressure. Then, $50 \mathrm{~mL}$ of chloroform and $5 \mathrm{~mL}$ of acetic anhydride were added to the residue, and the mixture was stirred for $2 \mathrm{~h}$ and concentrated under reduced pressure. In order to remove the acetyl group in the glycomonomer, the mixture was stirred with $100 \mathrm{~mL}$ of ammonia-methanol solution $(1: 1)$ at room temperature for $2 \mathrm{~d}$. After the removal of excess ammonia-methanol solution under reduced pressure, the co-products such as $N$ - $p$-vinylbenzyl acetamide were extracted with chloroform from the residue, and then the ethanol soluble part was collected and concentrated again. The residual, the xylaric type monomer (10), was collected on the glassfilter and purified by the reprecipitation from ethanol- $n$-hexane system; Yield, $2.8 \mathrm{~g}$ (56\%), m.p., 141-142 ${ }^{\circ} \mathrm{C} .{ }^{1} \mathrm{H}$ NMR (7.5\%, DMSO$\left.d_{6}, 25^{\circ} \mathrm{C}\right) \delta$, ppm; $8.2(\mathrm{t}, 1 \mathrm{H}$, amide $\mathrm{NH}), 7.4(\mathrm{~d}, 2 \mathrm{H}, 2,6-$ position of phenyl $\mathrm{CH}), 7.3(\mathrm{~d}, 2 \mathrm{H}, 3,5$-position of phenyl $\mathrm{CH})$, $6.7\left(\mathrm{dd}, 1 \mathrm{H}, \mathrm{CH}=\mathrm{CH}_{2}\right), 5.8\left(\mathrm{~d}, 1 \mathrm{H}, \mathrm{CH}=\mathrm{CH}_{2}(\mathrm{cis})\right), 5.2(\mathrm{~d}, 1 \mathrm{H}$, $\mathrm{CH}=\mathrm{CH}_{2}($ trans $\left.)\right), 4.3\left(\mathrm{~d}, 2 \mathrm{H}\right.$, benzyl $\left.\mathrm{CH}_{2}\right), 4.1\left(\mathrm{~d}, 1 \mathrm{H},{ }^{2}\right.$ or ${ }^{4} \mathrm{CH}-$ $\mathrm{CONH}), 4.0\left(\mathrm{t}, 1 \mathrm{H},{ }^{4}\right.$ or $\left.{ }^{2} \mathrm{CH}-\mathrm{COOH}\right), 3.9\left(\mathrm{~d}, 1 \mathrm{H},{ }^{3} \mathrm{CH}\right), 3.0-4.2$ (bs, $4 \mathrm{H}, \mathrm{OH}),{ }^{13} \mathrm{C}$ NMR $\left(7.5 \%\right.$, DMSO- $\left.d_{6}, 25^{\circ} \mathrm{C}\right) \delta, \mathrm{ppm}$; $175.6(\mathrm{NH}-\underline{C} \mathrm{O}), 173.1(\underline{C} \mathrm{OOH}), 139.4\left(\mathrm{NH}-\mathrm{CH}_{2}-\underline{C}\right.$ (phenyl)), 


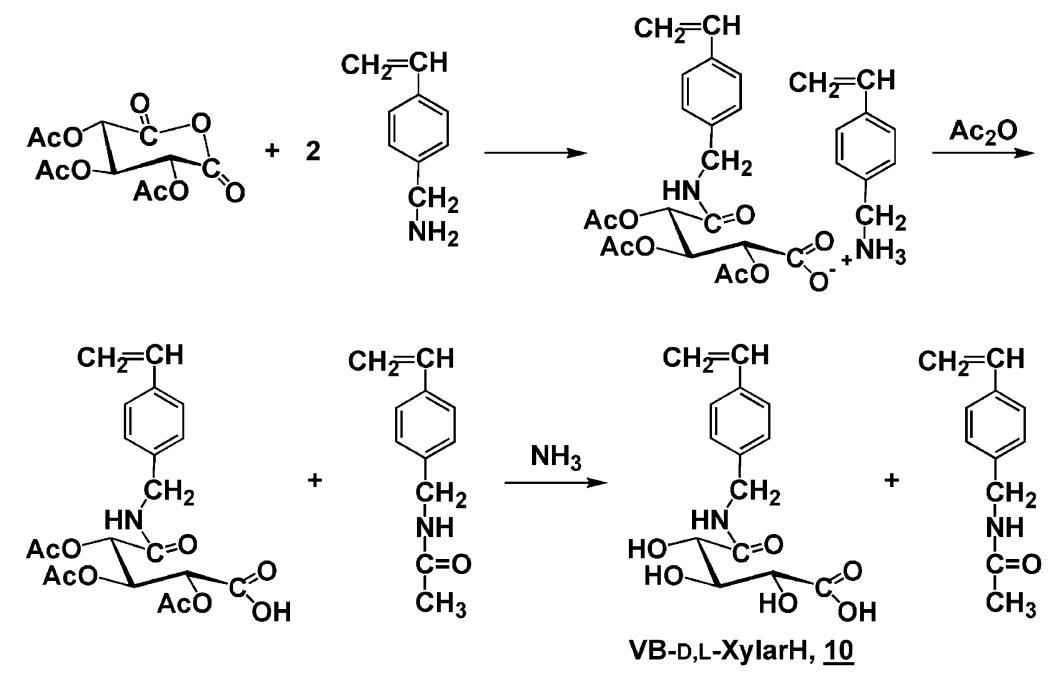

Scheme 12.

$136.2\left(\mathrm{CH}_{2}=\underline{C} \mathrm{H}\right), 135.3\left(\mathrm{CH}_{2}=\mathrm{CH}-\underline{C}\right.$ (phenyl)), $127.2(3,5-$ position of phenyl $\underline{C}$ ), 125.8 (2,6-position of phenyl $\underline{C}$ ), 113.4 $\left(\underline{C} \mathrm{H}_{2}=\mathrm{CH}\right), 72.7\left({ }^{2}\right.$ or $\left.{ }^{4} \underline{C}\right), 72.0\left({ }^{3} \underline{C}\right), 70.7\left({ }^{2}\right.$ or $\left.{ }^{4} \underline{C}\right)$, and 41.4 (benzyl $\underline{C} \mathrm{H}_{2}$ ). IR (KBr disk): 3486, 3436, 3390, 3324, 3253 $\mathrm{cm}^{-1}\left(v_{\mathrm{O}-\mathrm{H}}\right.$ and $\left.v_{\mathrm{N}-\mathrm{H}}\right), 1724 \mathrm{~cm}^{-1}\left(v_{\mathrm{C}=\mathrm{O}}\right.$, carboxyl $), 1610 \mathrm{~cm}^{-1}$ ( $v_{\mathrm{C}=\mathrm{O}}$, amide), $1537 \mathrm{~cm}^{-1}\left(v_{\mathrm{N}-\mathrm{H}}\right) .[\alpha]^{25} \mathrm{D}=+0,3^{\circ}$ (DMSO, C $1.0)$.

Tartaric type monomer (11) was also prepared in a similar method to that for $\underline{10}$; Yield, $56 \%$. m.p., $186-187^{\circ} \mathrm{C} .{ }^{1} \mathrm{H}$ NMR: $\left(7.5 \%\right.$, DMSO- $\left.d_{6}, 25^{\circ} \mathrm{C}\right) \delta, \mathrm{ppm} ; 8.1(\mathrm{t}, 1 \mathrm{H}$, amide $\mathrm{N} H), 7.4$ (d, 2H, 2,6-position of phenyl $\mathrm{CH}$ ), 7.3 (d, 2H, 3,5-position of phenyl $\mathrm{CH}), 6.7\left(\mathrm{dd}, 1 \mathrm{H}, \mathrm{CH}=\mathrm{CH}_{2}\right), 5.8(\mathrm{~d}, 1 \mathrm{H}$, $\mathrm{CH}=\mathrm{CH}_{2}$ (cis)), $5.2\left(\mathrm{~d}, 1 \mathrm{H}, \mathrm{CH}=\mathrm{CH}_{2}\right.$ (trans)), $4.3(\mathrm{~d}, 1 \mathrm{H}$, $\left.{ }^{2} \mathrm{CH}\right), 4.2\left(\mathrm{~d}, 2 \mathrm{H}\right.$, benzyl $\left.\mathrm{CH}_{2}\right), 4.0\left(\mathrm{~d}, 1 \mathrm{H},{ }^{3} \mathrm{CH}\right), 5.5-6.8$ (bs, $2 \mathrm{H}, \mathrm{OH}),{ }^{13} \mathrm{C}$ NMR $\left(7.5 \%\right.$, DMSO- $\left.d_{6}, 25^{\circ} \mathrm{C}\right) \delta, \mathrm{ppm} ; 173.9$ (NH- $\underline{C} \mathrm{O}), 171.6$ ( $\underline{C} \mathrm{OOH}), 139.3$ (NH-CH- $\underline{C}$ (phenyl)), 136.5 $\left(\mathrm{CH}_{2}=\underline{C} \mathrm{H}\right), 135.6\left(\mathrm{CH}_{2}=\mathrm{CH}-\underline{C}\right.$ (phenyl)), 127.4 (3,5-position of phenyl $\underline{C}), 126.0$ (2,6-position of phenyl $\underline{C}), 113.8(\underline{C}$ $\mathrm{H}_{2}=\mathrm{CH}$ ), 73.2 (NH-CO- $\left.\underline{C}\right), 71.8(\underline{C}-\mathrm{COOH})$, and 40.8 (benzyl $\left.\underline{C} \mathrm{H}_{2}\right)$. IR (KBr disk): $3507,3382,3282 \mathrm{~cm}^{-1}$ ( $v_{\mathrm{O}-\mathrm{H}}$ and $v_{\mathrm{N}-\mathrm{H}}$ ), $1733 \mathrm{~cm}^{-1}$ ( $v_{\mathrm{C}=\mathrm{O}}$, carboxyl), $1633 \mathrm{~cm}^{-1}\left(v_{\mathrm{C}=\mathrm{O}}\right.$, amide), 1537 $\mathrm{cm}^{-1}\left(v_{\mathrm{N}-\mathrm{H}}\right) .[\alpha]^{25}{ }_{\mathrm{D}}=+57,7^{\circ}$ (DMSO, C 1.0).

\section{Copolymerization of Glycomonomers with Acrylamide (AAm)}

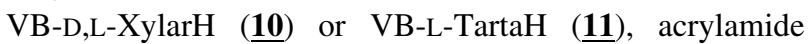
(AAm) and azobisisobutyronitrile were dissolved in dimethyl sulfoxide in testing tubes. After degassing three times in a cooling bath, the tubes were sealed and heated in a bath controlled at $60{ }^{\circ} \mathrm{C}$ for $24 \mathrm{~h}$. Then, the tubes were cooled down at $-20^{\circ} \mathrm{C}$ for quenching. After the seal was broken, the solution was poured to a large amount of chloroform and the resulting polymers were collected on a glassfilter. The polymers were purified by dialysis (cut off 3500) with water and the lyophilization. The copolymer composition was estimated from the intensity ratio of the signals in the ${ }^{1} \mathrm{H}$ NMR.
Estimation of Inhibition Value of Different Glycopolymers and Monomers for $\boldsymbol{\beta}$-Glucuronidase Activity

A model compound, for the $\beta$-D-glucuronide conjugates $p$ nitrophenyl $\beta$-D-glucuronide (9) $(7 \mathrm{mmol} / \mathrm{L})$, was hydrolyzed with $14 \mathrm{IU} / \mathrm{L}$ of $\beta$-glucuronidase in an acetic buffer solution $(\mathrm{pH}=4.7)$ at $37^{\circ} \mathrm{C}$ in presence or absence of $0.002-6.67$ $\mathrm{mmol} / \mathrm{L}$ of the glyco unit in the glycopolymers or glycomonomers. The same lot No. of the $\beta$-glucuronidase was used for the hydrolytic test in the absence and presence of each inhibitor. The hydrolytic rate was estimated from the time dependence of the absorbance of the freed $p$-nitrophenol at $400 \mathrm{~nm}$. The inhibition value of the glycopolymers (\%) was calculated from the hydrolytic rate in the presence or absence of $0.002-6.67 \mathrm{mmol} / \mathrm{L}$ of the glyco unit in the glycopolymers.

The Lineweaver-Burk plot was attempted by using the data determined in $0.4-1.4 \mathrm{mM}$ of $p$-nitrophenyl $\beta$-D-glucuronide in the presence of different amounts of the glycomonomers and glycopolymers.

\section{RESULTS AND DISCUSSION}

\section{Monomer Synthesis}

A styrene monomer, $N$ - $p$-vinylbenzyl-D,L-xylaramic acid (VB-D,L-XylarH, 10), was newly synthesized as shown in Scheme 12. Two equivalents of $p$-vinylbenzylamine were added to 2,3,4-tri- $O$-acetyl-meso-xylaric anhydride in ethyl acetate and the mixture was stirred at $40{ }^{\circ} \mathrm{C}$ for $1 \mathrm{~d}$. The resulting crude salt (14) was acetylated with acetic anhydride in chloroform for $2 \mathrm{~h}$. Then acetyl groups in the glycomonomer were selectively hydrolyzed in ammonia-methanol solution at room temperature for $2 \mathrm{~d}$. The co-products such as $N-p$ vinylbenzyl acetamide were removed as a chloroform soluble part from the residue and subsequently the glycomonomer ( $\underline{\mathbf{1 0}})$ was obtained as an ethanol soluble part at $40^{\circ} \mathrm{C}$. Total yield was about $56 \%$; m.p. $141-142{ }^{\circ} \mathrm{C}$.

Another monomer, $N$ - $p$-vinylbenzyl-L-tartaramic acid (VBL-TartaH, 11), was also prepared using L-tartaric anhydride as a 


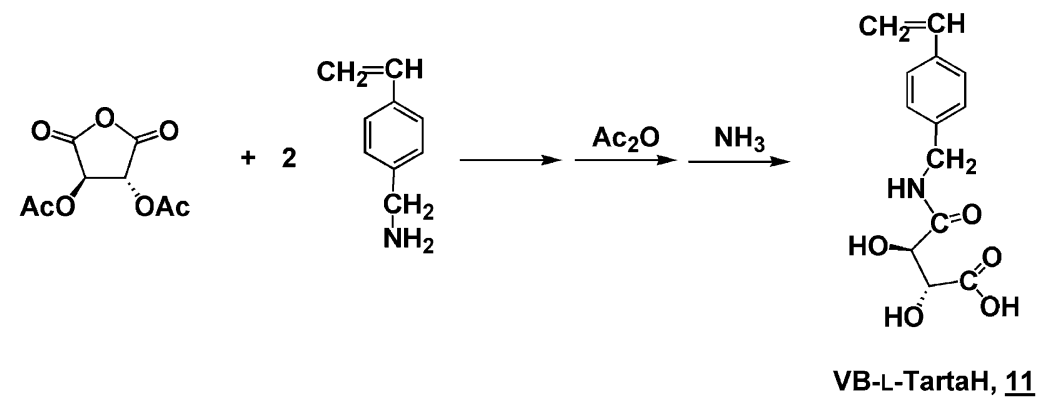

Scheme 13.

Table I. The radical copolymerization of the glycomonomers ( $\underline{\mathbf{1 0}}$ and $\underline{\mathbf{1 1}})$ with acrylamide ${ }^{\mathrm{a}}$

\begin{tabular}{|c|c|c|c|c|c|c|c|c|c|c|c|c|}
\hline \multirow{2}{*}{$\begin{array}{l}\text { Run } \\
\text { No. }\end{array}$} & \multicolumn{2}{|c|}{ Glycomonomer } & \multirow[b]{2}{*}{$\begin{array}{l}\text { AAm } \\
\text { mmol }\end{array}$} & \multirow{2}{*}{$\begin{array}{l}\text { Mole fraction } \\
\text { of } M_{1} \text { in feed }\end{array}$} & \multirow[b]{2}{*}{$\begin{array}{l}{[\mathrm{M}]_{0}} \\
\mathrm{~mol} / \mathrm{L}\end{array}$} & \multirow{2}{*}{$\begin{array}{l}\text { AlBN } \\
\mathrm{mol} \%\end{array}$} & \multirow[b]{2}{*}{$\underset{\mathrm{h}}{\mathrm{Time}}$} & \multicolumn{3}{|c|}{ Polymer } & \multirow[b]{2}{*}{$\begin{array}{c}M_{\mathrm{n}}^{\mathrm{c}} \\
\times 10^{-4}\end{array}$} & \multirow[b]{2}{*}{$M_{\mathrm{w}} / M_{\mathrm{n}}{ }^{\mathrm{c}}$} \\
\hline & $\mathrm{M}_{1}$ & $\begin{array}{c}\mathrm{mg} \\
(\mathrm{mmol})\end{array}$ & & & & & & $\begin{array}{l}\text { Resulting } \\
\text { polymer }\end{array}$ & $\begin{array}{l}\text { Yield } \\
\mathrm{mg}\end{array}$ & $\begin{array}{c}\text { Mole fraction of } \\
\underline{10} \text { or } \underline{11}^{\mathrm{b}}\end{array}$ & & \\
\hline 1 & $\underline{10}$ & $177(0.6)$ & 2.4 & 0.20 & 3.0 & 1.00 & 24 & $\underline{12}$ & 217 & 0.25 & 1.56 & 1.90 \\
\hline 2 & $\underline{10}$ & $177(0.6)$ & 2.4 & 0.20 & 3.0 & 0.25 & 24 & $\underline{12}$ & 177 & 0.35 & 2.96 & 1.72 \\
\hline 3 & $\underline{10}$ & $177(0.6)$ & 2.4 & 0.20 & 3.0 & 0.05 & 36 & $\underline{12}$ & 124 & 0.42 & 4.14 & 1.98 \\
\hline 4 & $\overline{10}$ & $170(0.6)$ & 2.4 & 0.20 & 1.5 & 1.00 & 24 & $\underline{12}$ & 210 & 0.22 & 0.84 & 1.53 \\
\hline 5 & $\underline{10}$ & $295(1.0)$ & 4.0 & 0.20 & 1.0 & 0.30 & 24 & $\underline{12}$ & 336 & 0.41 & 1.32 & 1.57 \\
\hline 6 & $\underline{11}$ & $316(1.2)$ & 4.8 & 0.20 & 6.0 & 0.13 & 12 & $\underline{13}$ & 318 & 0.30 & 8.80 & 2.62 \\
\hline 7 & $\underline{11}$ & $158(0.6)$ & 2.4 & 0.20 & 1.5 & 1.00 & 12 & $\underline{13}$ & 110 & 0.23 & 0.88 & 2.95 \\
\hline 8 & $\underline{11}$ & $474(1.8)$ & 4.2 & 0.30 & 6.0 & 0.13 & 12 & $\underline{13}$ & 408 & 0.41 & 11.3 & 2.70 \\
\hline 9 & $\underline{11}$ & $239(0.9)$ & 2.1 & 0.30 & 3.0 & 0.25 & 12 & $\underline{13}$ & 72 & 0.50 & 4.7 & 1.91 \\
\hline
\end{tabular}

a Solvent, DMSO; temp., $60^{\circ} \mathrm{C}$. ${ }^{\mathrm{b}} \mathrm{By}{ }^{1} \mathrm{H}$ NMR in $\mathrm{D}_{2} \mathrm{O}$. ${ }^{\mathrm{c} B y} \mathrm{SEC}$ in acetic buffer (standard, PEG).

starting material in a similar method (Scheme 13); yield, 68\%; m.p. $186-187^{\circ} \mathrm{C}$.

Both two new monomers $\underline{\mathbf{1 0}}$ and $\underline{\mathbf{1 1}}$ are soluble in water, $\mathrm{DMF}$, and DMSO at room temperature and in ethanol and methanol at $60^{\circ} \mathrm{C}$, but insoluble in chloroform, diethyl ether, benzene and acetone.

\section{Copolymerization of the Glycomonomers ( $\underline{10}$ and 11) with} Acrylamide (AAm)

The radical copolymerization of the glycomonomers containing D,L-xylaric and L-tartaric pendants $(\underline{\mathbf{1 0}}$ and $\underline{\mathbf{1 1}})$ with acrylamide (AAm), on which the mole fraction of the glycomonomers in feed was 0.2 or 0.3 , proceeded in DMSO in a homogeneous phase at $60^{\circ} \mathrm{C}$. The resulting copolymers were precipitated in chloroform, purified by dialysis (cut off 3500) in water and isolated by the subsequent lyophilization (Table I).

The resulting copolymers, P(VB-D,L-XylarH-co-AAm) (12) and P(VB-L-TartaH-co-AAm) (13), were dissolved in water, methanol and DMSO, at room temperature, but were insoluble in chloroform, benzene, diethyl ether and ethyl acetate. The number average molecular weight estimated by size-exclusion chromatography in acetic buffer $(\mathrm{pH}=4.7)$ was found to be controlled by the initial monomer concentration and the initiator concentration in the range from $8.8 \times 10^{3}$ to $11 \times$ $10^{4}$. The copolymer composition was determined from the signal intensity in their ${ }^{1} \mathrm{H}$ NMR spectrum as shown in Table I. The copolymers obtained in the present work are speculated to be the random copolymers, because the copolymer composition of a similar glycopolymer, P(VB-6-D-GlucaH-co-AAm) $\underline{\mathbf{5}}$, depended upon the mole fraction of glycomonomer in feed on the radical copolymerization as reported in our previous article. $^{6}$

Inhibition of $\beta$-Glucuronidase Activity by Different Glycopolymers and Glycomonomers

A model compound for the $\beta$-D-glucuronide conjugates of xenobiotics, $p$-nitrophenyl $\beta$-D-glucuronide (9), was hydrolyzed with $\beta$-glucuronidase in the absence or presence of the resulting glycopolymers ( $\underline{\mathbf{1 2}}$ and $\underline{\mathbf{1 3}})$, the corresponding monomers $(\underline{\mathbf{1 0}}$ and $\underline{\mathbf{1 1}})$ or saccharic acids. The inhibition value (\%) was calculated from the hydrolytic rates of the substrate in the absence and presence of the copolymers, monomers or saccharic acids ( $\mathrm{v}_{0}$ and $\mathrm{v}$, respectively) as shown in eq 1 .

$$
\text { Inhibition value }(\%)=\left\{\left(\mathrm{v}_{0}-\mathrm{v}\right) / \mathrm{v}_{0}\right\} \times 100
$$

As shown in Figure 1, inhibition value of the glycopolymer bearing D,L-xylaric moiety, P(VB-D,L-XylarH-co-AAm) (12), was found to be $50 \%$ even at the lower range of the concentration of the saccharic unit such as $0.05 \mathrm{mmol} / \mathrm{L}$, and increased with the concentration of up to $70 \%$ at $6.67 \mathrm{mmol} / \mathrm{L}$. On the other hand, the corresponding glycomonomer, VB-D,LXylarH (10), and meso-xylaric acid inhibited insignificantly at a lower concentration $(<0.1 \mathrm{mmol} / \mathrm{L})$, although their inhibition values rose at higher concentration, except L-tartaric acid.

As summarized in Figure 2, the glycopolymer bearing Ltartaric moiety, P(VB-L-TartaH-co-AAm) (13), inhibited the enzyme effectively at the lower concentration range of the saccharic unit, and the inhibition value deteriorated similarly in the order of the copolymer ( $\underline{\mathbf{1 3}})$, monomer $(\underline{\mathbf{1 1}})$, and L-tartaric acid. 


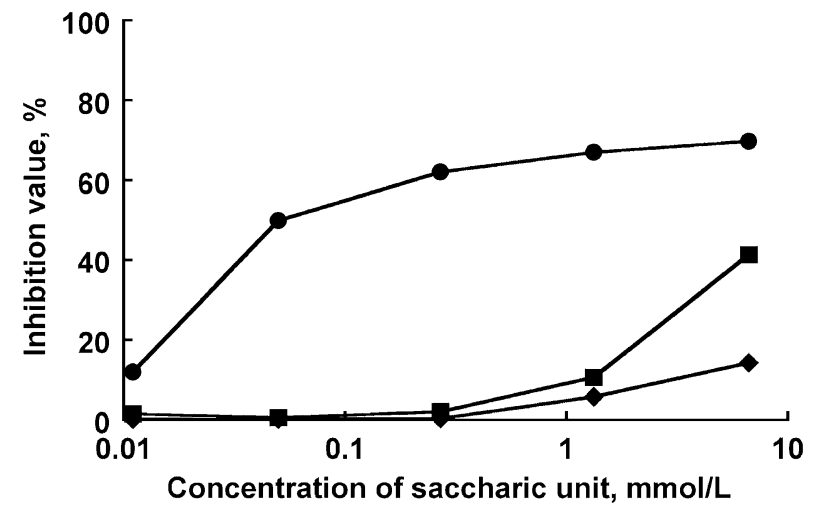

Figure 1. Inhibition of the $\beta$-glucuronidase activity by the xylaric series inhibitors at $37^{\circ} \mathrm{C}$ ( $p$-nitrophenyl $\beta$-D-glucuronide $(\mathbf{9}), 7 \mathrm{mmol} / \mathrm{L}$; $\beta$-glucuronidase, $14 \mathrm{IU} / \mathrm{L})$. 0 ; P(VB-D,L-XylarH-co-AAm) (12), glycomonomer unit, $22 \%, M_{\mathrm{n}}=0.84 \times 10^{4}$ : $\square$; VB-meso-XylarH (10): $\diamond$; D-Xylaric acid.

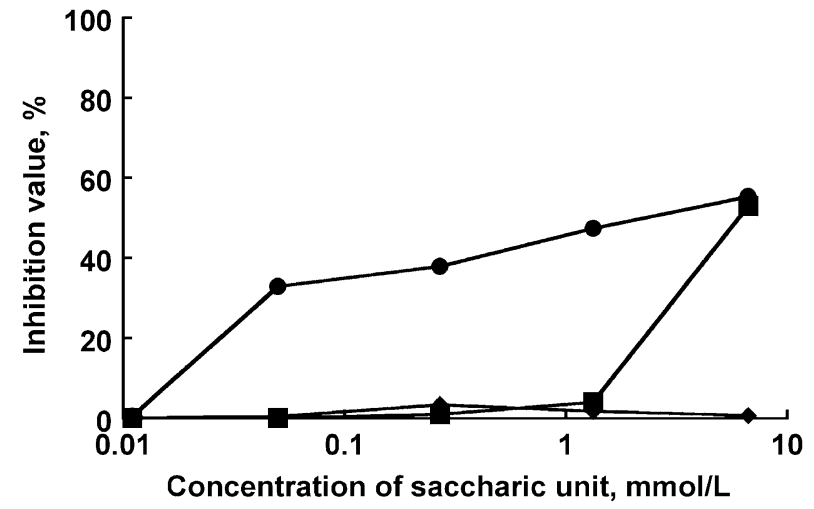

Figure 2. Inhibition of the $\beta$-glucuronidase activity by the tartaric series inhibitors at $37^{\circ} \mathrm{C}$ ( $p$-nitrophenyl $\beta$-D-glucuronide $(\underline{9}), 7 \mathrm{mmol} / \mathrm{L}$; $\beta$-glucuronidase, $14 \mathrm{IU} / \mathrm{L})$. 0 ; P(VB-L-TartaH-co-AAm) (13), glycomonomer unit, $23 \%, M_{\mathrm{n}}=0.88 \times 10^{4}$ : $\square$; VB-L-TartaH (11): $\bullet$; L-Tartaric acid.

Another noteworthy point is in the fact that glycomonomers $\underline{\mathbf{1 0}}$ and $\underline{\mathbf{1 1}}$ having $p$-vinylbenzyl group inhibited more strongly than the corresponding saccharic acids at a higher concentration. The hydrophobicity of $p$-vinylbenzyl group may also participate in the inhibition behavior. The effect of the hydrophobic group is now being investigated from the view point of the interaction with a hydrophobic part in the enzyme, and will be reported in the near future.

These effective inhibitions of the glycopolymers ( $\underline{\mathbf{1 2}}$ and $\underline{\mathbf{1 3}})$ should be caused by the linkage of the glycomonomer unit along the polymer chain. Therefore the glycomonomer units are inferred to exist as a cluster even in the lower concentration and the glycopolymers show a positive cluster effect on the inhibition.

Figure 3 shows that the inhibition values of copolymer $\underline{\mathbf{1 2}}$ (P(VB-D,L-XylarH-co-AAm)) and copolymer 13 (P(VB-LTartaH-co-AAm)) were lower than that in the case of glycopolymer $\underline{\mathbf{5}}$ (P(VB-6-D-GlucaH-co-AAm)) reported in our previous work. ${ }^{6,7}$ The glucaric moiety in copolymer $\mathbf{5}$ has potentially similar conformation to the glucuronic moiety in

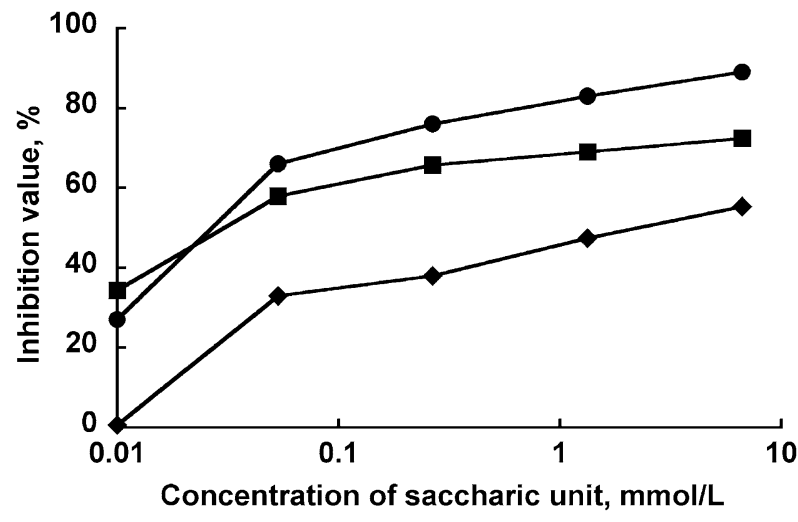

Figure 3. Inhibition of the $\beta$-glucuronidase activity by the different glycopolymers at $37^{\circ} \mathrm{C}$ ( $p$-nitrophenyl $\beta$-D-glucuronide (9), $7 \mathrm{mmol} / \mathrm{L}$

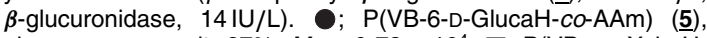
glycomonomer unit, $27 \%, M_{n}=0.73 \times 10^{4}: \square$; P(VB-D,L-XylarHco-AAm) (12), glycomonomer unit, $22 \%, M_{n}=0.84 \times 10^{4}$ : $\mathrm{P}(\mathrm{VB}-\mathrm{L}-\mathrm{TartaH}-\mathrm{Co}-\mathrm{AAm})$ (13), glycomonomer unit, $23 \%, M_{\mathrm{n}}=$ $0.88 \times 10^{4}$.

the $\beta$-D-glucuronide conjugates. In contrast, the chain length of xylaric and tartaric moieties in glycopolymer $\underline{\mathbf{1 2}}$ and $\underline{\mathbf{1 3}}$ are shorter than that of D-glucaric acid. Therefore, the similarity of the molecular structure, especially, the chain length may also be one important factor for the inhibition.

Although the tartaric-type inhibitor (13) was less effective to the $\beta$-glucuronidase activity than the glucaric- and xylaric-type inhibitors ( $\underline{\mathbf{5}}$ and $\underline{\mathbf{1 2}}$ ), it is still useful, because L-tartaric anhydride, which is a key starting material for the corresponding glycopolymer (13), is commercially available and less expensive. On the other hand, D-glucaro-6,3-lactone and xylaric anhydride for the synthesis of the glycomonomers (1 and $\underline{\mathbf{1 0}}$ ), respectively, are expensive and/or necessary to be prepared in the laboratory before use.

\section{Lineweaver-Burk Plot}

The inhibition behavior can be distinguished by judging from the each extrapolating line on Lineweaver-Burk plot ${ }^{17,18}$ and typical examples of Lineweaver-Burk plot were shown in Figure 4.

In the case of competitive inhibition, each line crosses on the vertical axis (Figure 4A), whereas in the case of noncompetitive inhibition, each line crosses on the horizontal axis (Figure 4B). In the case of uncompetitive inhibition, each line becomes parallel (Figure 4C). On the other hand, each line intersects in the second quadrant in the case of the mix-type of competitive and noncompetitive inhibition (Figure 4D) and cross in third quadrant in the case of the mix-type of noncompetitive and uncompetitive inhibition (Figure 4E), respectively.

The hydrolytic rate (v) in different concentration of $\beta$ glucuronide $\underline{9}$ with $\beta$-glucuronidase was determined in the presence of the glycopolymers having tartaric and xylaric pendants ( $\underline{\mathbf{1 3}}$ and $\underline{\mathbf{1 2}})$ (Figures 5 and 6). $\mathrm{V}_{\max }, \mathrm{K}_{\mathrm{m}}$ and $\left(\mathrm{K}_{\mathrm{m}} /\right.$ $\mathrm{V}_{\max }$ ) for the line in the absence of the inhibitor and the apparent values of $\mathrm{V}_{\max }{ }^{\mathrm{I}}, \mathrm{K}_{\mathrm{m}}^{\mathrm{I}}$ and $\left(\mathrm{K}_{\mathrm{m}} / \mathrm{V}_{\max }\right)^{\mathrm{I}}$ for the line in 

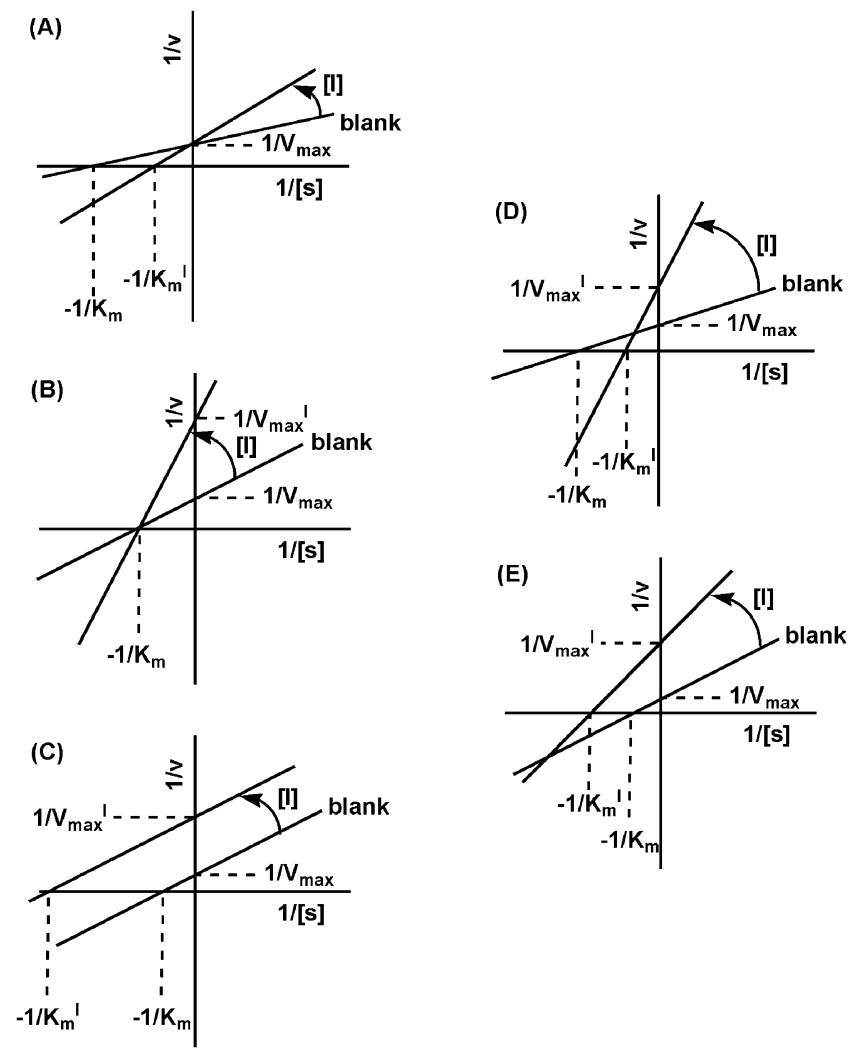

Figure 4. The typical examples of Lineweaver-Burk plot. (A) competitive inhibition, (B) noncompetitive inhibition, (C) uncompetitive inhibition, (D) mix-type of competitive and noncompetitive inhibition and (E) mix-type of noncompetitive and uncompetitive inhibition.

the presence of the inhibitors were estimated from the slope and intercepts of each line and summarized in Table II.

In the case of hydrolytic test using glycopolymer $\underline{\mathbf{1 3}}$ as a macromolecular inhibitor (Figure 5), the intercept of the horizontal axis was found to be constant and not to depend on the concentration of the macromolecular inhibitor $(\underline{\mathbf{1 3}})$, but the intercept of the vertical axis to be dependent upon the concentration. In other words, $\mathrm{K}_{\mathrm{m}}$ and $\mathrm{K}_{\mathrm{m}}{ }^{\mathrm{I}}$ were constant and independent upon the concentration of the inhibitor, and $\mathrm{V}_{\max }$ and $\mathrm{V}_{\max }{ }^{\mathrm{I}}$ were dependent upon the concentration of the inhibitor as shown in Table II. Thus, the tartaric-type glycopolymer is presumed to inhibit the enzyme noncompetitively. The tartaric-type glycopolymer binds probably not only the enzyme (E) but also the enzyme-substrate complex (ES). This fact is remarkably different from the competitive inhibition by glucaric-type copolymer $\mathbf{5}$ reported in our previous article. ${ }^{6}$ In the Lineweaver-Burk plot for the copolymer $\mathbf{5}$, the intercept of the vertical axis, that corresponds to $1 / \mathrm{V}_{\max }$ and $1 / \mathrm{V}_{\max }$, was constant and independent on the concentration of the copolymer $\mathbf{5}$, but that of the horizontal axis, that corresponds to $-1 / \mathrm{K}_{\mathrm{m}}$ and $-1 / \mathrm{K}_{\mathrm{m}} \mathrm{I}$, depend upon the concentration. The glucaric-type glycopolymer should bind to the active site of the enzyme and prevent the binding of the substrate.

The Lineweaver-Burk plot for the xylaric-type glycopolymer 12 was more complicated (Figure 6). Both intercepts of horizontal and vertical axes were dependent upon the concen-

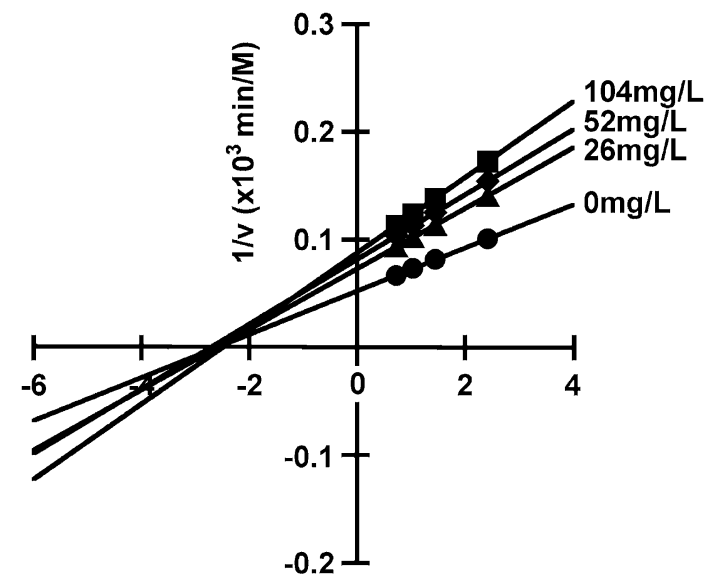

$1 /[\mathrm{S}]\left(\mathrm{mM}^{-1}\right)$

Figure 5. Lineweaver-Burk plot for the kinetic data on the hydrolysis of $p$ nitrophenyl $\beta$-D-glucuronide (9) by $\beta$-glucuronidase in the presence of $\mathrm{P}(\mathrm{VB}-\mathrm{L}-\mathrm{TartaH}-\mathrm{co}-\mathrm{AAm})$ (13). glycomonomer unit, $23 \%$, $M_{\mathrm{n}}=0.80 \times 10^{4}$

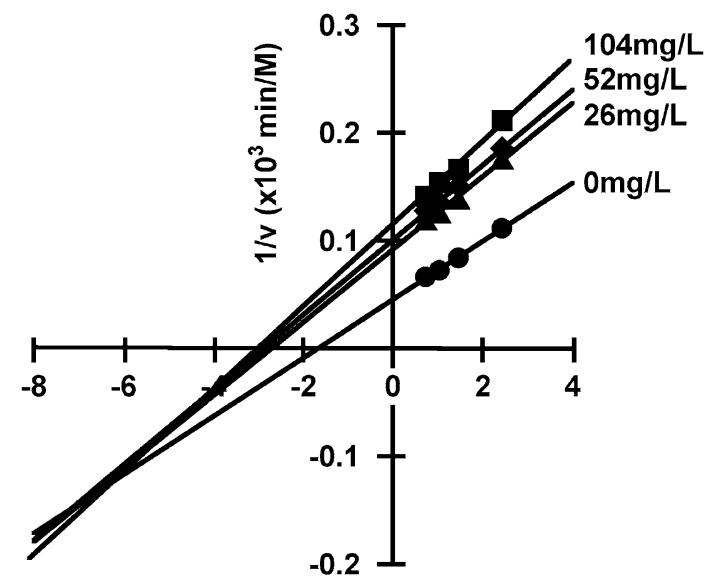

$1 /[\mathrm{S}]\left(\mathrm{mM}^{-1}\right)$

Figure 6. Lineweaver-Burk plot for the kinetic data on the hydrolysis of $p$ nitrophenyl $\beta$-D-glucuronide (9) by $\beta$-glucuronidase in the presence of $\mathrm{P}(\mathrm{VB}-\mathrm{D}, \mathrm{L}-\mathrm{XylarH}-\mathrm{co}-\mathrm{AAm})$ (12). glycomonomer unit, $41 \%$, $M_{\mathrm{n}}=1.32 \times 10^{4}$.

Table II. The kinetic data on the hydrolysis of $p$-Nitrophenyl $\beta$-glucuronide with $\beta$-glucuronidase in the presence of macromolecular inhibitors at $37^{\circ} \mathrm{C}$

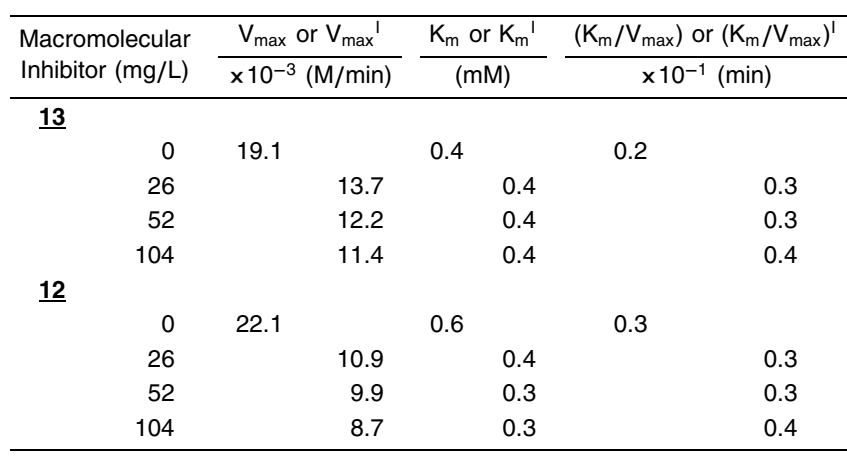




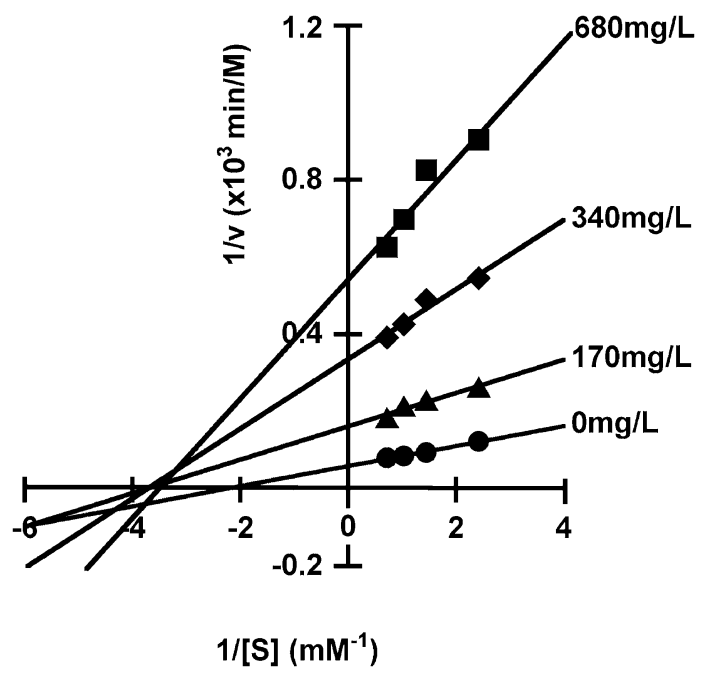

Figure 7. Lineweaver-Burk plot for the kinetic data on the hydrolysis of $p$ nitrophenyl $\beta$-D-glucuronide (9) by $\beta$-glucuronidase in the presence of VB-L-TartaH (11).

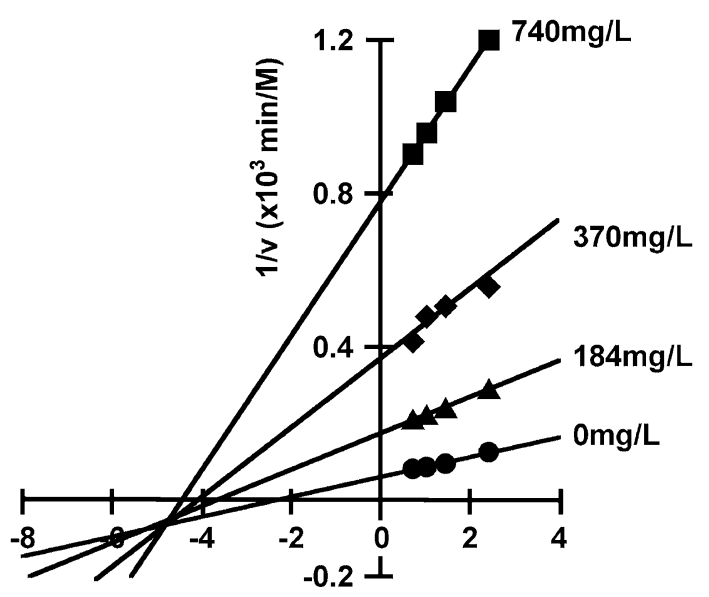

$1 /[\mathrm{S}]\left(\mathrm{mM}^{-1}\right)$

Figure 8. Lineweaver-Burk plot for the kinetic data on the hydrolysis of $p$ nitrophenyl $\beta$-D-glucuronide (9) by $\beta$-glucuronidase in the presence of VB-D,L-XylarH (10).

tration. In addition, the extrapolating lines on the all glycopolymer concentration and the line in the absence of the glycopolymer were found to cross over in the third quadrant. Judging from the intersection position the behavior of glycopolymer $\underline{\mathbf{1 2}}$ is supposed to be a mix-type of noncompetitive and uncompetitive inhibition. Such a inhibition behavior may reflect the fact that the glycopolymer $\mathbf{1 2}$ contains both Dand L-xylaric moieties.

Lineweaver-Burk plot was also applied to the kinetic data on the hydrolysis in the presence of the corresponding glycomonomers ( $\underline{\mathbf{1 1}}$ and $\underline{\mathbf{1 0}}$ ) (Figures 7 and 8) and $\mathrm{V}_{\max }, \mathrm{K}_{\mathrm{m}}$ and $\mathrm{K}_{\mathrm{m}} /$ $\mathrm{V}_{\max }$ in the absence of the inhibitor and the apparent values of $\mathrm{V}_{\max }{ }^{\mathrm{I}}, \mathrm{K}_{\mathrm{m}}{ }^{\mathrm{I}}$ and $\left(\mathrm{K}_{\mathrm{m}} / \mathrm{V}_{\max }\right)^{\mathrm{I}}$ in the presence of glycomonomers were shown in Table III.

As shown in Figures 7 and 8, both Lineweaver-Burk plots of the glycomonomers were quite similar to those of the
Table III. The kinetic data on the hydrolysis of $p$-Nitrophenyl $\beta$-glucuronide with $\beta$-glucuronidase in the presence of monomeric inhibitors at $37^{\circ} \mathrm{C}$

\begin{tabular}{|c|c|c|c|}
\hline \multirow{2}{*}{$\begin{array}{l}\text { Macromolecular } \\
\text { Inhibitor (mg/L) }\end{array}$} & $\mathrm{V}_{\max }$ or $\mathrm{V}_{\max } \mathrm{I}^{\mathrm{I}}$ & \multirow{2}{*}{$\frac{\mathrm{K}_{\mathrm{m}} \text { or } \mathrm{K}_{\mathrm{m}}{ }^{\mathrm{I}}}{(\mathrm{mM})}$} & \multirow{2}{*}{$\frac{\left(\mathrm{K}_{\mathrm{m}} / \mathrm{V}_{\max }\right) \text { or }\left(\mathrm{K}_{\mathrm{m}} / \mathrm{V}_{\max }\right)^{\prime}}{\times 10^{-1}(\mathrm{~min})}$} \\
\hline & $\times 10^{-3}(\mathrm{M} / \mathrm{min})$ & & \\
\hline \multicolumn{4}{|l|}{$\underline{11}$} \\
\hline 0 & 18.1 & 0.5 & 0.3 \\
\hline 170 & 6.2 & 0.3 & 0.4 \\
\hline 340 & 3.0 & 0.3 & 0.9 \\
\hline 680 & 1.8 & 0.3 & 1.5 \\
\hline \multicolumn{4}{|l|}{$\underline{10}$} \\
\hline 0 & 16.8 & 0.4 & 0.3 \\
\hline 184 & 15.8 & 0.3 & 0.5 \\
\hline 370 & 2.7 & 0.2 & 0.9 \\
\hline 740 & 1.3 & 0.2 & 1.8 \\
\hline
\end{tabular}

corresponding glycopolymers, respectively. Taking into consideration of the low inhibition ability of polyacrylamide as reported previously, ${ }^{6}$ the mechanism of the glycopolymer can be mainly caused by their corresponding glycomonomer. Thus, the inhibition with glycomonomer $\underline{\mathbf{1 1}}$ should be noncompetitive, whereas that with the glycomonomer $\underline{\mathbf{1 0}}$ may be a mixtype of noncompetitive and uncompetitive inhibition.

Although the figure is not presented here, the inhibition with glycomonomer $\underline{\mathbf{1}}$ is competitive, and similar to that of glycopolymer $\underline{\mathbf{5}}$, which will be reported in a separated paper in the near future.

As above-mentioned, the competitive inhibition by the glucaric-type copolymer, $\underline{\mathbf{5}}$, may reflect the similarity of its molecular structure to that of the $\beta$-glucuronide unit in the substrate (9). In other words, the noncompetitive inhibition by the tartaric-type copolymer $\underline{\mathbf{1 3}}$ and a mixed-type inhibition by the xylaric copolymer $\underline{\mathbf{1 2}}$ might reflect the unsimilarity of their molecular structure to that of the $\beta$-glucuronide unit. The length of the carbon chains and the configuration of the saccharic units in the glycopolymers $\underline{\mathbf{1 2}}$ and $\underline{\mathbf{1 3}}$ are significantly different from those of the $\beta$-glucuronide unit in the substrate $\mathbf{9}$ as shown in Figure 9. Nevertheless, the glycopolymers 12 and $\underline{13}$ should be useful because of their inhibition ability.

In summary xylaric and tartaric copolymers $\underline{\mathbf{1 2}}$ and $\underline{\mathbf{1 3}}$ synthesized in the present work were found to inhibit the activity of $\beta$-glucuronidase and to show "cluster effect" as well as the glucaric copolymer $\underline{\mathbf{5}}$ reported in our previous work. The inhibition tendency became lower with the shortening of the
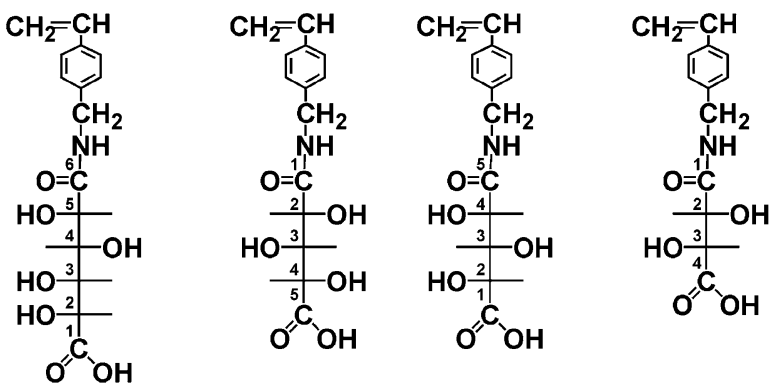

VB-6-D-GlucaH, 1

VB-D,L-XylarH, $\underline{10}$

VB-L-TartaH, 11

Figure 9. Fisher projections of VB-6-GlucaH (1), VB-D,L-XylarH (10), and VB-L-TartaH (11). 
carbon chain in the saccharic moieties. However, the inhibition behavior of the copolymers $\underline{\mathbf{1 2}}$ and $\underline{\mathbf{1 3}}$ is different from that of glucaric-type copolymer $\underline{\mathbf{5}}$, which inhibits the enzyme competitively.

Acknowledgment. The authors thank Professors Masao Kawakita and Yasutada Imamura of Kogakuin University for their experimental guidance and helpful discussion on the present results. This work was partly supported by Grant-inAid for High Technology Research Center in Private Universities from the Japanese Ministry of Education, Culture, Sports, Science and Technology.

Received: April 26, 2008

Accepted: June 19, 2008

Published: August 6, 2008

\section{REFERENCES}

1. A. J. Glazko, W. A. Dill, and L. M. Wolf, J. Pharmacol. Exp. Ther., 104, 452 (1952).

2. C. Sacco and J. E. J. Calabrese, J. Environ. Sci. Health Toxical., A27, 1249 (1992).

3. C. Sacco, W. E. McEwen, and E. Calabrese, J. Hum. Exp. Toxical., 12, 181 (1993)
4. C. Sacco and E. J. Calabrese, J. Hum. Exp. Toxical., 13, 759 (1994).

5. K. Hashimoto, R. Ohsawa, N. Imai, and M. Okada, J. Polym. Sci. Part A: Polym. Chem., 37, 303 (1999).

6. K. Hashimoto, R. Ohsawa, and H. Saito, J. Polym. Sci., Part A. Polym. Chem., 37, 2773 (1999).

7. K. Hashimoto, H. Saito, and R. Ohsawa, J. Polym. Sci., Part A: Polym. Chem., 44, 4895 (2006).

8. M. C. Karunairatnam and G. A. Levvy, Biochem. J., 44, 599 (1949).

9. G. A. Levvy, Biochem J., 52, 464 (1952).

10. T. Delahunty and D. Hollander, Comp. Biochem. Physiol., 86, 565 (1987).

11. C. A. March, Biochem. J., 99, 22 (1966).

12. A. Kiyomoto, S. Harigaya, S. Ohshima, and T. Morita, Biochem. Pharmacal., 12, 105 (1963).

13. M. Marselos, G. Dutton, and O. Hanninen, Biochem. Pharmacol., 24, 1855 (1975).

14. A. Macfadyen and K. Ho, J. Hepatology, 9, 552 (1989).

15. C. Dwivedi, W. I. Heck, A. A. Donie, S. Larroya, and T. E. Webb, Biochem. Med. Metab. Biol., 43, 83 (1990).

16. Z. Walaszek, M. Hanausek-Qalaszek, and T. Webb, Carcinogenesis, 5, 767 (1984).

17. L. Stryer, in "Biochemistry," 3rd ed., Freeman, New York, 1993, p. 189.

18. H. Lineweaver and D. Burk, J. Am. Chem. Soc., 56, 658 (1934).

19. C. E. Cantrell, D. E. Kiely, G. J. Abruscato, and J. M. Riordan, J. Org. Chem., 42, 3562 (1977).

20. W. Zhou, M. J. Kurth, Y. Hsieh, and J. M. Krochta, Macromolecules, 32, 5507 (1999). 